\title{
POSSÍVEIS CAMINHOS PARA A UTILIZAÇÃO DO MEDO NO CONTO "SEM OLHOS" DE MACHADO DE ASSIS
}

THAMIRES GONÇALVES

Universidade do Estado do Rio de Janeiro

Rio de Janeiro, Rio de Janeiro, Brasil

Resumo: Na literatura brasileira não observamos uma "escola" da literatura do horror, que é a denominação usada para os textos que buscam provocar medo nos leitores. Poucos são os autores que se encaixariam nessa denominação, o exemplo mais comum seria Noite na taverna de Álvares de Azevedo. Neste artigo, pretendese demonstrar que o medo utilizado no conto "Sem olhos" está intrinsecamente ligado à estrutura da narrativa. Para isso, são apresentadas algumas interpretações sobre a maneira como esse sentimento aparece na construção da narrativa, para, então, refletir sobre: a utilização do medo como controle social; suas reações físicas; o medo como prazer estético; campo e cidade como espaços narrativos.

Palavras-chave: medo; prazer estético; controle social; Machado de Assis

\section{POSSIBLE USES OF FEAR IN THE SHORT STORY, "SEM OLHOS," BY MACHADO DE ASSIS}

Abstract: Brazilian literature does not have an observable "school" of horror literature, which is the name used for describing texts that seek to stoke fear in readers. There are few authors who would fit that description, the most common example would be Noite na taverna by Álvares de Azevedo. In this article, we intend to demonstrate that fear is used in the story "Semolhos" by Machadode Assis, and is inextricably linked to its structure. With this in mind, we present various interpretations on how this feeling participates in the construction of the narrative to consequently discuss: the use of fear as a social control; the physical reactions it produces; fear as aesthetic pleasure; and the reversal of the common fears associated to the narrative spaces of the countryside and the city.

Keywords: Fear; social control; aesthetic pleasure; Machadode Assis. 


\section{Considerações iniciais}

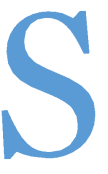

e procurarmos pelo significado da palavra medo no dicionário, chegaremos a um estado afetivo suscitado pela consciência do perigo; uma ansiedade irracional ou fundamentada; receio; temor. Pensando nisso, é muito fácil imaginar o que nos provoca medo: um filme de terror, um inseto, uma rua escura à noite, um assalto. Muitas são as origens ou possibilidades do medo.

Na literatura brasileira não observamos uma "escola" da literatura do horror, que é a denominação usada para os textos que buscam provocar medo nos leitores. Na historiografia da literatura brasileira é comum que se enquadre apenas Noite na taverna, de Álvares de Azevedo, como um texto de horror, ou pelo menos o que mais se aproximaria a essa escola. No entanto, há exemplares de autores de narrativas ficcionais brasileiras que utilizam o medo em sua tessitura, por exemplo: Júlia Lopes de Almeida, com "Os porcos"; Bernardo Guimarães, com "A dança dos ossos"; Medeiros e Albuquerque, com Noivados trágicos; João do Rio, com "Dentro da noite"; Monteiro Lobato, com "Bugio moqueado". É possível perceber que a maioria das obras citadas são contos, algo comum na literatura produzida no Brasil, quando se trata de literatura de horror.

Não é comum ouvir que a literatura produzida por Machado de Assis seja de horror, e não é realmente. No entanto, neste artigo pretende-se demonstrar que o medo é utilizado neste conto. Para isso, são apresentadas algumas interpretações sobre a maneira como esse sentimento aparece na construção da narrativa. Assim, propõe-se discutir: o medo utilizado como controle social; as reações físicas ao medo; o medo como prazer estético; e a inversão dos medos comuns no espaço narrativo do campo e da cidade.

A partir da observação atenta do conto, será possível debater sobre os elementos que tornam possível a leitura de "Sem olhos" como um texto que utiliza o medo para a construção da narrativa, mas sem se tornar uma história de horror clássica como os romances/contos escritos por Edgar Allan Poe, Mary Shelley, Horace Walpole, H.P. Lovecraft ou Stephen King. 


\section{Maria do Céu e bacharel Antunes: medo e controle social}

O conto "Sem olhos" foi publicado originalmente em 1876 no Jornal das Famílias, editado por Garnier. ${ }^{1}$ Anteriormente à publicação desse conto, Machado já publicara três romances, três livros de poesia e dois de contos, além de contribuições frequentes em diversos periódicos. Dessa forma, podemos considerar que o autor já era conhecido e contava com um público cativo e específico, quando se tratava de periódicos. Eis o entrecho do conto.

"Sem olhos" inicia na casa do casal Vasconcelos, que recebia quatro amigos: Bento Soares, sua mulher Maria do Céu, o bacharel Antunes e o desembargador Cruz. A conversa, que antes do chá estava tranquila, passou a temas mais lúgubres. Os convivas começam, então, a discutir a existência ou não de fantasmas, e o desembargador Cruz afirma temer assombrações e narra - por insistência dos presentes - um episódio que lhe acontecera na juventude, a fim de demonstrar o motivo de seus temores.

A história de Cruz ocorreu quando ele era apenas um estudante recémchegado ao Rio de Janeiro, onde se instalou na rua da Misericórdia. Seu vizinho de cima era um homem "de quarenta anos que parecia ter mais de cinquenta, tão alquebrado e encanecido que estava". ${ }^{2}$ Inicialmente, o homem lhe pareceu um lunático, mas, com o passar do tempo, um sentimento de amizade foi construído entre o velho homem e o jovem estudante. Às portas da morte, Damasceno Rodrigues - este era o nome do vizinho - lhe contou uma história que teria acontecido com ele anos antes.

Damasceno era médico e conheceu um homem, também médico, casado com Lucinda. O casal morava em um engenho em Jeremoabo, interior da Bahia. A mulher era linda; o homem, taciturno e ciumento. Damasceno se torna amigo do homem e passa a nutrir um sentimento de compaixão pela mulher, que sofria nas mãos do marido. Um dia, em visita à propriedade dos dois, encontra Lucinda, e numa troca de olhares o amor mútuo é confirmado. O marido, que presenciou a cena, fica enfurecido, e o medo sentido por Lucinda a faz perder os sentidos. Damasceno ainda tenta argumentar, mas suas palavras não são levadas em conta pelo marido. Sem coragem para enfrentar o homem naquele momento, o jovem vai embora.

\footnotetext{
${ }^{1}$ Baptiste-Louis Garnier chegou ao Brasil em 1844, aqui fundou a Livraria Garnier, que dirigiu até sua morte em 1893. Além de suas contribuições para o melhoramento da indústria livreira no Brasil, sua livraria foi palco de reuniões e encontros literários. Com grande tino comercial, Garnier empenhou-se em conquistar o público feminino, sua livraria passou a publicar, entre outros, o Jornal das Famílias, periódico no qual Machado fez publicações.

${ }^{2}$ ASSIS, Obra completa, v. 2, p. 1445.
} 
Tempos depois, volta ao engenho para confirmar o rumor que ouvira. Segundo os moradores da redondeza, a mulher teria morrido. Chegando lá, Damasceno encontra o marido de Lucinda, que lhe diz que ela está viva, embora tenha sido castigada. Diz o homem a Damasceno: "Vê, disse ele, só lhe castiguei os olhos". ${ }^{3}$

Ao encontrar Lucinda, assusta-se ao perceber que o marido lhe arrancara os olhos: "os olhos da pobre moça tinham desaparecido; ele os vazara, na véspera, com um ferro em brasa...". ${ }^{4} \mathrm{E}$ o marido finaliza dizendo que "os olhos delinquiram, os olhos pagaram!". ${ }^{5}$

De volta ao quarto do enfermo, o então jovem desembargador Cruz fica horrorizado com a história do velho, que nesse momento já estava entregue ao delírio e apontava na direção da parede. Ao olhar para a mesma direção, vê a figura de uma mulher sem olhos.

Olhei; e podem crer que ainda hoje não me esqueci o que ali se passou. De pé, junto à parede, vi uma mulher lívida, a mesma do retrato, ${ }^{6}$ com os cabelos soltos, e os olhos.... Os olhos, esses eram duas cavidades vazias e ensanguentadas. ${ }^{7}$

O jovem, diante do choque, desmaia e só acorda na tarde do dia seguinte. Damasceno morrera naquela manhã. Dias depois, o jovem Cruz descobre fatos sobre a vida do vizinho que impossibilitam que a história seja real. Voltando à sala do casal Vasconcelos, todos atribuem a visão à situação estressante vivida por Cruz. Maria do Céu tem uma reação diferente, ela baixa os olhos e estremece. O bacharel Antunes também se mostra tocado pela narrativa e vai à janela à procura de ar fresco.

A reação final de Maria do Céu espelha a reação de Lucinda, que, por medo de seu marido, estremecia e baixava os olhos ao ver Damasceno. Diz ele: "Lucinda não me olhava nunca. Era medo, era talvez intimação do marido. Se me falava alguma vez era secamente e por monossílabos". ${ }^{8}$

No entanto, se Maria do Céu se perturbou muito com o fim trágico de Lucinda, isto só acorre após tomar ciência da história. Durante todo o conto,

\footnotetext{
${ }^{3}$ Idem, p. 1454.

${ }^{4}$ Ibidem.

${ }^{5}$ Ibidem.

${ }^{6}$ Damasceno mostrou uma foto de sua jovem amada antes de lhe narrar a trágica história. Porém, esse fato foi omitido aqui, para tornar a narrativa do enredo mais objetiva.

${ }^{7}$ ASSIS, Obra completa. v. 2, p. 1454.

${ }^{8}$ Idem, p. 1453.
} 
é possível perceber que ela flertava com o bacharel Antunes. Logo no início da narrativa, quando tomavam chá, surge a primeira atitude de flerte entre os dois.

- Queres mais chá, Maria? -perguntou a dona da casa à esposa de Bento Soares, que acabava de beber a última gota do seu.

- Aceito.

O bacharel Antunes apressou-se a receber a xícara de d. Maria do Céu, com uma cortesia e graça, que lhe rendeu o mais doce dos sorrisos. ${ }^{9}$

A expressão "o mais doce dos sorrisos" traz uma atitude que não combina com uma senhora casada, acompanhada de seu marido, visitando amigos. Mais adiante, quando a conversa se bifurca, era esperado que os grupos se formassem entre homens e mulheres; no entanto, o bacharel prefere ficar com as senhoras e falar sobre toilette. Em outra passagem, que descreve Maria do Céu, o narrador (em terceira pessoa) ressalta a admiração que o bacharel nutria pela senhora.

Quieta, podiam pô-la num altar; mas, se movia os olhos, era pouco menos que um demônio. Tinha um jeito peculiar de usar deles que enfeitiçou alguns anos antes a gravidade de Bento Soares, fenômeno que o bacharel Antunes achava o mais natural do mundo. Vestia nessa noite um vestido cor de pérola, objeto da conversa entre o bacharel e as duas senhoras. Antunes, sem contestar que a cor de pérola ia perfeitamente à esposa de Bento Soares, opinava que era geral acontecer o mesmo às demais cores; donde se pode razoavelmente inferir que em seu parecer a porção mais bela de Maria não era o vestido, mas ela mesma. ${ }^{10}$

Importante observar que é o narrador em terceira pessoa que dá os indícios da postura indecorosa de Maria do Céu e Antunes. Ao frisar que "se pode razoavelmente inferir" que Antunes não apreciava apenas o vestido, mas sim a pessoa de Maria do Céu, dá pistas ao leitor sobre a atitude dos dois, deixando um sinal de atenção para o que viria a seguir.

A segunda situação que denuncia o ar de romance entre os dois ocorre quando Maria do Céu desdenha pela primeira vez do medo de Cruz.

${ }^{9}$ Idem, p. 1443-44.

${ }^{10}$ Idem, p. 1444. 
- Os fantasmas são fruto do medo - disse esta, sentenciosamente. Quem não tem medo não vê fantasmas.

- Você não tem medo? - perguntou a dona da casa

- Sempre há de ter algum, opinou Vasconcelos.

- Não tenho medo de nada nem de ninguém. ${ }^{11}$

Se antes da narrativa de Cruz, Maria não tem "medo de nada nem de ninguém", após a narrativa ela passa a ter medo, sim. O medo que Maria diz não ter é um medo baseado em crenças; porém, ao fim da narrativa, o medo que ela passa a sentir é o medo do outro. Medo de que Bento Soares pudesse fazer-lhe o mesmo que o marido de Lucinda fizera a ela, caso cometesse um adultério, por exemplo. Se Maria inicia o conto com um medo facilmente desmistificável (o medo de fantasmas), ela passa a nutrir um medo real, o medo que advém da consequência de um ato, como a traição, por exemplo.

Para Delumeau, o medo é fundamentalmente o medo da morte. Essa sensação nos acompanhará por toda a nossa existência, pois é intrínseca à condição humana. Sendo o homem um ser racional, é o único que pode antecipar sua morte. Além de ser capaz de direcionar seu medo a objetos não concretos. Diferente dos animais em geral, que reagem quando ameaçados e/ou em perigo iminente de morte, o homem pode reagir a estímulos externos e sentir medo de uma rua escura à noite, supondo que pode sofrer um ato de violência. Se durante muito tempo estava baseado nas forças da natureza, doenças e epidemias, o medo evoluiu e vem se tornando, cada vez mais, o medo do próprio homem.

Ainda segundo Delumeau, o medo pode ser dividido em dois grupos: o medo natural e o medo cultural. O primeiro diz respeito a doenças, epidemias, pestes, fenômenos naturais; o segundo se refere ao medo do outro, isto é, o medo do desconhecido. Então, se Maria do Céu no início da narrativa não tinha temores, é porque sua referência era o medo natural. A personagem tem outra perspectiva sobre suas atitudes e suas possíveis consequências somente após ouvir a narrativa de Cruz. O referencial de medo de Maria do Céu mudou a partir do sentimento de empatia que nutriu por Lucinda ao longo da narrativa. Ao sentir medo no fim do conto, ela se coloca no lugar de Lucinda.

O sentimento de medo da morte, ou de autopreservação, é uma emoção natural, que funciona como um mecanismo de defesa que nos mantém vivos. Em Os medos de ontem e de hoje, Delumeau afirma que atualmente as pessoas

${ }^{11}$ Idem, p. 1445. 
não temem mais confessar seus medos, o que faz crescer o sentimento de insegurança nas sociedades. Sendo o medo uma desconfiança em relação à natureza humana, esse sentimento pauta uma concepção de formação da sociedade, que se inclina à preservação da segurança pessoal.

Todas as reações de Maria do Céu e Antunes ao fim do conto conferem ao texto de Machado de Assis um peculiar tom de ensinamento moral. O medo construído em "Sem olhos" tem um objetivo didático e uma mensagem final clara: Mulheres, não traiam seus maridos! Portanto, não é de se estranhar que este conto tenha sido originalmente publicado em um jornal que tinha como público leitor mulheres em sua maioria.

\section{Casal Vasconcelos e Bento Soares: o medo como prazer estético}

O interesse dos outros personagens de "Sem olhos" pela história de Cruz e o que sentiram a partir da audição dela são bem diferentes do que foi tratado até agora. Eles não sentem medo, e sim prazer; ou melhor, têm prazer em sentir medo. Como dito antes, o desembargador Cruz não desejava contar sua história, mas o fez apenas por insistência de seus convivas, como se pode observar na passagem abaixo:

Mas o auditório tinha a curiosidade aguçada, e o próprio mistério e recusa do desembargador faziam crescer o apetite. Os homens insistiram; as senhoras fizeram coro com eles. Cruz imolou-se ao sufrágio universal. [...]

O desembargador olhou para os interlocutores, como a ver se era possível evitar a narração; mas a curiosidade estava tão pendente de todos os olhos, que era impossível resistir. ${ }^{12}$

Para Hitchcock, o medo que se sente ao ver um filme de terror - ou, no caso dos personagens do conto, ouvindo uma história de fantasmas - é um medo indireto, sentido em segundo grau e vivenciado por meio de uma experiência não real. Através da narrativa de Cruz, os personagens puderam sentir medo estando em segurança. Esse medo lhes gerava prazer. Se o casal Vasconcelos e Bento Soares instigaram Cruz a contar sua história é porque desejavam ouvi-la, eles sabiam que a narrativa poderia lhes provocar medo, mas, como estavam a salvo dentro da casa, eram conscientes de que nenhum

${ }^{12}$ Idem, p. 1445. 
mal lhes aconteceria. Sendo assim, pode-se concluir que procuravam prazer através da dor. A isso, Burke chamou deleite. Para ele, esse tipo de prazer está sempre vinculado ao sofrimento e indica a "sensação que acompanha a eliminação da dor ou do perigo". ${ }^{13}$

Ainda sobre o que levou esses personagens a instigarem Cruz a contar a terrível história, devemos levar em conta a questão da curiosidade. Segundo Burke, a curiosidade é o mais superficial dos sentimentos humanos e precisa ser a todo tempo alimentado por novidades. Cruz contou sua história apenas porque seus amigos lhe pediram, e eles fizeram isso porque a tentação era grande demais. Vejamos um trecho que evidencia isso:

- Você não tem medo? - perguntou a dona da casa.

- Tanto como deste leque.

- Sempre há de ter algum - opinou Vasconcelos.

- Não tenho medo de nada nem de ninguém.

- Pode ser - interveio o desembargador; - mas se visse o que eu vi uma vez, estou certo de que ficaria apavorada.

- Alguma bruxa?

- O diabo?

- Um defunto à meia-noite?

- Um duende?

Cruz empalidecera.

- Falemos de outra coisa - disse ele. ${ }^{14}$

O diálogo acima reproduzido retrata como a curiosidade da plateia obrigou Cruz a iniciar a narrativa. A série de inquirições (Alguma bruxa? O diabo? Um defunto à meia-noite? Um duende?) reafirma o caráter extraordinário do objeto da curiosidade, que só é instigada por algo que não é corriqueiro.

O casal Vasconcelos e Bento Soares experimentam a mesma reação ao longo do conto. Esta é transferida para o leitor, que por sua vez tem sua curiosidade aguçada a cada pausa dos narradores, seja ele Damasceno ou o jovem Cruz. Todas essas paradas contribuem para a construção de um suspense maior, que culmina no ato de violência do marido de Lucinda e na aparição do fantasma da mulher para o rapaz. Vejamos como essa tensão é construída.

${ }^{13}$ BURKE, Uma investigação filosófica sobre a origem de nossas ideias do sublime, p. 48.

${ }^{14}$ ASSIS, Obra completa, v. 2, p. 1445. 
A história contada por Damasceno tem três pausas que geram tensão em três escalas narrativas diferentes. A tensão é sentida pelo jovem Cruz, no momento em que ouvira a história de Damasceno; é sentida por aqueles que estavam presentes na sala dos Vasconcelos quando Cruz rememora o ocorrido; e, em última instância, é sentida pelo leitor, que recebe toda essa carga graças à narrativa em moldura de "Sem olhos".

Quanto às pausas, a primeira delas ocorre depois que o vizinho de Cruz entrega ao jovem estudante uma caixa que continha papéis velhos e uma fotografia de uma bela mulher, que possuía "os mais expressivos olhos". ${ }^{15}$ Damasceno não quer ver a fotografia e sua estranha reação gera curiosidade sobre quem seria a mulher. Nesse momento a história é suspensa. Esse mecanismo de pausa e retomada da história pelos narradores gera tensão e curiosidade no leitor/ouvinte.

Damasceno interrompeu-se; arrependia-se talvez; e eu não ousava, em tal situação, mostrar-me indiscreto e curioso. Ele entretanto atava o maço de papéis e a miniatura com um cadarço velho, e entregou-me tudo. ${ }^{16}$

A segunda pausa ocorre um pouco adiante, depois do incidente em que Damasceno e Lucinda trocam olhares e são surpreendidos pelo marido. Nesse momento, a narrativa de Damasceno é interrompida mais uma vez e o leitor/ouvinte é trazido de volta à realidade.

Estas recordações pareciam abater o enfermo. A voz, ao chegar àquela palavra, era fraca e rouca; ele fez uma longa pausa, cobrindo os olhos com as mãos ocas e transparentes. Alguns minutos depois continuou: $\left[\ldots . . .^{17}\right.$

Esses períodos de suspensão fazem com que o leitor/ouvinte se questione: Lucinda morreu?; o que o marido fará com ela?; o que ele fazia com a mulher para que tivesse tal reação? Antes da terceira pausa da narrativa, o leitor/ouvinte é ainda mais instigado:

Lucinda havia morrido; e a pessoa que deu esta notícia benzeu-se supersticiosamente e não revelou mais nada, apesar das minhas

\footnotetext{
${ }^{15}$ Idem, p. 1452.

${ }^{16}$ Ibidem.

${ }^{17}$ Idem, p. 1453.
} 
instâncias. Que teria havido? A ideia de que o marido a houvesse assassinado, apoderou-se de meu espírito; mas eu não ousava formular a pergunta. Indagando mais, ouvi de uns que ela cometera suicídio, de outros que desaparecera; enfim alguns criam que estava apenas doente às portas da morte. Esta diversidade de notícias era claro indício de que alguma coisa grave se passava ou estava passando. Fui ter à propriedade do marido, resoluto a saber tudo e a salvar a vida da inocente, se fosse possível....

Logo em seguida, o narrador interrompe mais uma vez, gerando ainda mais calafrios e perguntas.

Damasceno interrompeu-se de novo. Estava cansado e opresso. Pedi-lhe que suspendesse por algum tempo a narração e guardasse o fim para o dia seguinte, apesar da curiosidade que me picava interiormente. ${ }^{19}$

Todas essas pausas convergem para um clímax duplo, que inicia com a imagem de Lucinda sem olhos e culmina na aparição do fantasma da moça. No entanto, há outros mecanismos na estrutura do texto que acrescentam suspense à narrativa. Um exemplo disso se dá quando Damasceno adoece e o jovem Cruz vai a seu quarto e o vê.

Damasceno tinha os olhos cravados na parede; não me respondeu. Ia sair, para dar ordens ao meu criado, quando vi o enfermo sentar-se na cama, e olhando para a parede que lhe ficava ao lado dos pés, clamar aflito:

- Não! ainda não! Vai-te! Depois, daqui a um ano!... a dois... a três... Vaite, Lucinda! Deixa-me! ${ }^{20}$

Ao acrescentar a nova informação sobre Lucinda, enfatizando o medo e a apreensão que Damasceno demonstrou com esse novo personagem, o narrador instiga a desconfiança, levantando no leitor/ouvinte dúvidas sobre o passado do velho homem e o que teria acontecido a ele e a essa mulher.

Ainda durante sua enfermidade, Damasceno conta a Cruz algo, que inicialmente não faz sentido algum e provoca a curiosidade do personagem e conseguintemente no leitor. Diz o texto de Machado: "Mancebo, disse ele,

\footnotetext{
${ }^{18}$ Ibidem.

${ }^{19}$ Ibidem.

${ }^{20}$ Idem, p. 1449.
} 
com a voz cava; não olhe nunca para a mulher do seu próximo. Sobretudo não a obrigue a que ela olhe para o senhor. Comprará por esse preço a paz de sua vida toda". ${ }^{21}$

Todas essas informações novas, colocadas num contexto em que não fazem sentido de início, provocam questionamentos que só são respondidos ao longo da narrativa de Damasceno. Essas respostas que não chegam de imediato constroem o suspense da narrativa até que o clímax chega, trazendo $o$ alívio de não sermos Lucinda.

\section{Reações físicas ao medo}

Depois de explorar os possíveis caminhos para a construção do medo nos personagens, é interessante indagar sobre as reações físicas que eles apresentam ao longo da narrativa.

O medo pode ser categorizado em uma escala, seus graus variam do menor para o maior. Angústia, fobia e pânico fazem parte dessa escala e funcionam para ilustrar como o medo mexe com o corpo e os sentidos. A angústia se caracteriza pela capacidade humana de projetar (negativamente) o futuro a partir de uma situação qualquer. A fobia é um medo irracional diante de um objeto específico. O pânico é o medo que irrompe subitamente e causa efeitos fisiológicos. Dessa forma, o medo pode surgir a partir de uma situação concreta (um assalto, um inseto) ou não (a morte).

$\mathrm{O}$ medo pode provocar diversas reações físicas, que variam desde a aceleração ou diminuição de batimentos cardíacos, reações intestinais adversas, paralisia diante do perigo (catalepsia) ou uma exteriorização violenta. $^{22}$ No caso dos personagens do conto em questão, suas reações variam de desmaios e tremores a batimentos cardíacos descompassados. Essas reações físicas são utilizadas para dar maior veracidade aos sentimentos dos personagens, e para provocar um efeito de identificação entre personagem e leitor.

Além das reações já mencionadas de Lucinda, o jovem Cruz também sofreu com o medo instigado pela narrativa de Damasceno, apresentando uma grande variedade de sintomas relacionados a sua experiência

\footnotetext{
${ }^{21}$ Idem, p. 1451.

${ }^{22}$ Cf. DELPIERRE apud DELUMEAU, História do medo no ocidente, p. 189.
} 
sobrenatural. Quanto ao momento em que viu a aparição do fantasma da mulher na alcova do velho vizinho, narra o seguinte:

[...] senti esvaírem-se-me as forças e quase a razão. Batia-me o queixo, as pernas tremiam-me, tanto eu ficara gelado e atônito. Não sei o que se passou mais; não posso dizer sequer que tempo durou aquilo, porque os olhos se me apagaram também, e perdi de todo os sentidos.

[...] Passei uma noite cruel, entre a agitação e o abatimento. Sobre a madrugada dormi.

Acordei com sol alto. Pude então recordar a cena da véspera, e só a recordação me fazia tiritar e gelar a alma. ${ }^{23}$

O personagem descreve as reações físicas advindas da experiência de terror vivida. Tal acontecimento foi realmente marcante para o homem, refletindo em seu comportamento posterior. Mesmo depois de anos e após investigar a vida de Damasceno, descobrindo que sua história não poderia ser verídica, ${ }^{24} \mathrm{Cruz}$ ainda nutria um medo real da lembrança daquele episódio. O medo sentido por Cruz, portanto, é pautado unicamente nas impressões que o evento causou nele. É o medo de uma fantasia, criada por um homem possivelmente louco e às portas da morte, o que evidencia que seu sentimento é irracional e não controlável.

\section{O campo e a cidade: inversão do medo no locus horribilis}

"Sem olhos" possui uma estrutura narrativa em moldura, dividida da seguinte forma: a) a narrativa em terceira pessoa que apresenta o espaço da sala do casal Vasconcelos e seus respectivos personagens; b) a história de Cruz, contada aos amigos na sala dos Vasconcelos; c) a narrativa de Damasceno, contada a Cruz.

As três se passam em espaços diferentes: a casa do casal Vasconcelos, o Rio de Janeiro e o engenho no interior da Bahia. Como vimos, cada uma dessas narrativas se passa num locus diferenciado. A primeira e a segunda, acima citadas, se passam num espaço urbano, e a terceira num espaço rural.

\footnotetext{
${ }^{23}$ ASSIS, Obra completa, v. 2, p. 1454.

${ }^{24}$ Cruz descobre que a história do velho amigo não pode ser verídica, pouco depois de sua morte. Damasceno nunca esteve na Bahia, casou aos 22 anos em Santa Catarina, de onde só saiu aos trinta e três. Portanto, ter estado solteiro em Jeremoabo aos vinte e cinco seria impossível. Soube também que o retrato era de uma sobrinha que morreu solteira.
} 
Há, no entanto, uma interessante inversão dos monstros habituais de cada locus. No espaço urbano, o monstro que aterroriza Cruz é um fantasma; no espaço rural, o monstro que atormenta Lucinda e Damasceno é um homem. Para Cohen, os monstros criados em uma determinada cultura a representam.

O espaço rural é geralmente caracterizado pela presença de monstros criados e perpetuados pela tradição oral; por isso, a aparição de criaturas fantasmagóricas ou fantásticas é natural e esperada nas narrativas que se utilizam desse locus. Já nos espaços urbanos, o medo é caracterizado pela sensação de insegurança que os próprios espaços provocam no homem contemporâneo pela grande incidência de assaltos, sequestros, ou de violência em geral.

O que acontece em "Sem olhos" é justamente uma inversão de tudo isso, pois é no engenho em Jeremoabo, no interior da Bahia, que o medo do outro surge. O monstro de Damasceno não é um fantasma, um saci ou um boto; mas, sim, um marido violento e ciumento, que é capaz de arrancar os olhos da esposa com um ferro em brasa, porque ela olhou para outro homem. $\mathrm{Na}$ narrativa contada por Cruz, ele, quando jovem, teme um fantasma, uma figura que não deveria pôr medo algum nele, visto que a letalidade de um fantasma para um típico homem da cidade é muito pequena em comparação ao medo que provocaria num homem do campo.

Para Tuan, o medo existe na mente e tem origem em circunstâncias externas e consideradas ameaçadoras. A essas "construções" do medo arquitetadas pelo cérebro, chamamos paisagens do medo, que são as infinitas manifestações das forças do caos, naturais ou humanas. Elas se configuram a partir da combinação entre o espaço narrativo e a impressão de quem narra. Por isso, as manifestações de medo tanto de Cruz, quanto de Damasceno ou Lucinda se igualam. Portanto, os medos, se postos em uma balança, têm igual medida para a construção da narrativa.

\section{Considerações finais}

"Sem olhos" apresenta uma intrincada narrativa, repleta de idas e vindas temporais, convergindo num ensinamento moral, que se encaixa muito bem, ao levar-se em conta que é conto publicado num periódico voltado ao público feminino oitocentista.

A escolha pela utilização da narrativa em moldura confere ao conto verossimilhança. O narrador original, ou em terceira pessoa, atribui 
veracidade às informações das narrativas internas e transforma o ouvinte num voyeur, que espelha e induz as sensações do leitor. Além disso, o narrador interno reforça ao leitor o quão letal o monstro pode ser. Ao apresentar uma situação inicial cotidiana e natural e em seguida inserir outras duas narrativas, ambas com aspectos extraordinários, o conto cria uma atmosfera harmônica em meio ao caos produzido pela aparição de fantasmas e da extrema violência presente no conto.

Observamos uma atmosfera de suspense, gerada pelas interrupções nas narrativas, e um clímax criado pela aparição do elemento fantasmagórico; no entanto, embora "Sem olhos" se utilize do medo, a narrativa não se constrói em torno dele. O medo presente no conto é utilizado como uma ferramenta para discutir comportamentos sociais específicos, estabelecendo padrões de conduta e projetando as consequências de um comportamento corrupto.

\section{Referências}

ASSIS, Machado de. Obra completa. São Paulo: Nova Aguilar, 2015, vol. 2.

BURKE, Edmund. Uma investigação filosófica sobre a origem de nossas ideias do sublime. Tradução, apresentação e notas de Enid Abreu Dobránszky. Campinas, SP: Papirus, 1993.

COHEN, Jeffrey Jerome. A cultura dos monstros: sete teses. In: A pedagogia dos monstros: os prazeres e os perigos da confusão de fronteiras. Belo Horizonte: Autêntica, 2000, p. 25-55.

DELUMEAU, Jean. História do medo no Ocidente: 1300-1800, uma cidade sitiada. São Paulo: Companhia das Letras, 1989.

HITCHCOCK, Alfred. O prazer do medo. Tradução de Vera Lúcia Sodré. In: GOTTLIEB, Sidney, org. Hitchcock por Hitchcock: coletânea de textos e entrevistas. Rio de Janeiro: Imago, 1998.

MARTINS SILVA, Carlos Eduardo Cunha. A difusão do medo e a banalização das prisões provisórias: quando a exceção torna-se a regra do jogo; Orientador: Carlos Alberto Plastino Esteban. Rio de Janeiro: PUC, Departamento de Direito, 2011. Disponível em: http://www.maxwell.vrac.puc-rio.br/19656/19656_3.PDF. Acesso em: 18 jan. 2016.

MONTAIGNE, Michel de. Ensaios. Tradução de Sérgio Milliet. São Paulo: Nova Cultural, 1991. 
TUAN, Yi-Fu. Paisagens do medo. Tradução Lívia de Oliveira. São Paulo: Editora Unesp, 2005.

THAMIRES GONÇALVES possui graduação em Letras - Português/Latim pela Universidade do Estado do Rio de Janeiro (Uerj). Atualmente é mestranda em Literatura Brasileira na mesma instituição. Em 2015, fez parte da comissão organizadora do VI Seminário dos Alunos da Pós-Graduação em Letras da Uerj. Faz parte da equipe de edição do livro - a ser lançado - que é produto deste evento. Recentemente, apresentou comunicações em eventos realizados pelo Círculo Fluminense de Estudos Filológicos e Linguísticos (CiFEFiL) e pela Associação Brasileira de Literatura Comparada (Abralic), ambos com publicações em anais. E-mail: thamiresgoncalves2@hotmail.com.

Recebido: 20.06 .16

Aprovado: 29.09 .16 